during warm sunny days in winter, and again disappearing on the return of cold. This fact it is certainly very difficult to account for on any other supposition.

Argyll Lodge, Kensington, April in

ARGYLL

"In your letter received last night you tell me of an article in NATURE the author of which seems to deny that swallows ever hibernate, and asserts that no one has yet testified to the fact from his own personal observation. That, however, is a mistake, for $I$ have stated and I now repeat that $I$ have seen swallows in large numbers hibernating. The circumstances were these :-

"About twenty-five miles south of Teheran, the capital of Persia, there is a village called Kenara-gird near which is a stream of brackish water running in a deep bed with nearly perpendicular banks some forty or fifty feet high. Being largely impregnated with salt this stream is rarely if ever frozen, and in frosty weather is resorted to by flights of wild ducks. During a frost of unusual severity I went from Teheran to Kenara-gird, accompanied by Sir Henry Rawlinson, for the purpose of duckshooting, the severity of the frost promising good sport. Having slept at the village we next morning followed the downward course of the stream along the north bank, and had proceeded about a mile, I should think, when we came to a place where there had quite recently been a small land-slip. The brink of the bank to the extent of perhaps twenty feet in length, and ten or twelve broad in the middle, tapering off to each end, had slipped, but had not fallen down the bank. Between this detached portion and the perpendi. cular face about ten feet high, from which it had broken off, we saw, to our great surprise, a number of swallows, not less, I am sure, than twenty or thirty, lying, as I at first supposed, dead, but on taking up one of them I found that it was alive but dormant; it was warm and its

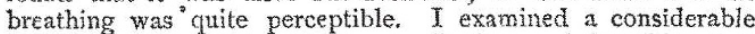
number, and found that they were all alive and breathing, but none of thein gave any sign of consciousness. My attention was then attracted to the perpendicular face on our left, from which the slip had broken off, and which was perforated by a vast number of holes each about the size of a rat-hole. On looking into such of these as I was tall enough to see into, I found in all of them swallows in the same dormant state. I was able with finger and thumb to pull out swallows from several of these holes, and in each case found that the hole which penetrated horizontally a considerable way into the bank, contained more swallows in the same condition. In no case did I see one lying on arother-they were all lying singly with their heads inwards, each head tcuching the tail of the bird before it. How far these holes penetrated into the bank, or what number of swallows each contained $I$ did not ascertain, but it is plain that the original entrance to these dormitories, must have been in the external face of the portion that had slipped, which as I have stated, was, in the middle, from ten to twelve feet thick. The holes in the undisturbed fortion may probably have been of equal or greater length, and if so the number of swallows hibernating there must have amounted to many hundreds."

Villa Poralto, Cannes, April 6

\section{The Swallows and Cuckoo at Mienton}

THE swallow that arrived here on March 19 remained solitary until April 5. Early that morning a second arrived and entered the same room as the first. I saw them flying about together in the forenoon, and these two remain the only feathered occupants of that chamber. In the afternoon of the same day, however, a party of ten arrived and distributed themselves among the houses.

Madame Valetta, of whom I spoke in my previous letter (NATURE, vol. xv., p. 488), assures me that not during the last fifty years has one swallow preceded its fellows by so long an interval as this year; but perhaps it is only that her attention has not been drawn so much to the subject. It is certain, how ever, that unless more are yet to come, the swallows are this year fewer than ordinary by more than one-half. The opinion cf the natives is that they have perished at sea.

I heard the cuckoo for the first time this year on April $\mathrm{r}$. But a lady had to'd me that she had heard it nearly a week before.

Cabrolles, près de Menton, France, April I3

\section{Greenwich as a Meteorological Observatory}

THE facts of observation appealed to by Mr. Eaton with the view of proving that Greenwich is, from artificial causes, more than half a degree warmer than the south-east of England generally, and is therefore not a suitable place for a meteorological observatory of the first order, evidently call for a closer critical examination than they have yet received. If from the sixteen stations within a radius of sixty miles from the metropolis given in the paper on "The Temperature of the British Islands," we omit those which are clearly inadmissible for the comparison with Greenwich owing to their position or to the short time during which observations were made, there remain the following eight stations as suitable for comparison:-Cardington, $52^{\circ} 7^{\prime}$ lat. N. ; Royston, $52^{\circ} 2^{\prime}$; Colchester, $51^{\circ} 53^{\prime}$; Hartwell, $5 I^{\circ} 49$; Oxford, $5^{1^{\circ}} 46^{\prime}$; Great Berkhamstead, $5 \mathrm{I}^{\circ} 45^{\prime}$; Chatham, $51^{\circ} 23^{\prime}$; and Aldershot, $5 \mathrm{r}^{\circ} 15^{\prime}$. The mean temperature of these eight stations, allowing for elevation, is $50^{\circ} \cdot 6$, and the mean temperature of Greenwich, $5 \mathbf{I}^{\circ} \cdot \mathbf{I}$, restilts substantially agreeing with those given by $\mathrm{Mr}$. Eaton.

It is necessary, however, to observe that the mean posi. tion of these places does not agree with that of Greenwich. Thus while the latitude of Greenwich is $51^{\circ} 28^{\prime}$ north, the mean latitude of the eight stations is $51^{\circ} 45^{\prime}$, or $0^{\circ} I 7^{\prime}$ farther north, their true mean position being about two miles due north of $\mathrm{St}$, Albans. For this difference in latitude a correction of fully $\mathrm{O}^{\circ} .2$ is required, judging from the position of the isothermal lines. The figures then stand thus: mean temperature of Greenwich, $5 \mathrm{I}^{\circ} \cdot \mathrm{I}$; of the eight stations, $50^{\circ} \cdot 8$. On comparing the monthly means of the eight stations with those of Greenwich, it is seen that the residual excess of Greenwich is all but wholly occa. sioned by the high mean temperatures of June, July, August, and September, which are in each case $0^{\circ} .9$ higher than the means of the eight stations, these eight stations being nearly all outside or on the outskirts of the patch of high temperature around London during the summer months. It follows that the $0^{\circ} \cdot 3$ of excess of annual temperature at Greenwich over the eight stations is accounted for by the bigher temperature of four out of the twelve months, and consequently cannot be due to artificial sources of heat in London, such as the consumption of fue].

When drawing the isothermals of the British Islands seven years ago, no district of Great Britain occasioned so mach trouble and uncertainty as the south-east of England, owing to the meagreness of the materials available for the purpose. Since, however, immediately to westward, the mean temperature of Oxford was seen to be $50^{\circ} \cdot 4$, Aldershot $51^{\circ} \cdot 2$, and Osborne $5 \mathrm{I}^{\circ} .8$, it was inferred as the most probable state of the case that the mean temperature increased southwards over the south-east. of England in the manner indicated by the annual isothermals accompanying the paper. This supposition was confirmed by the temperatures at Colchester and Chatham, the only two stations furnishing satisfactory data on the point, for while at Colchester, for instance, the mean temperature was $0^{\circ} .5$ lower than that of Greenwich, no less than $0^{\circ} 4$ of this difference was due to the lower temperature of the east coast at Colchester as com. pared with Greenwich during the five months beginning with December, when the temperature in the south of England increases from east to west.

The coast stations of the Channel could not be considered as furnishing authoritative evidence on the question, owing to the irregular distribution of their temperature, which seemed to indicate certain obscure and iil-understood causes in operation modifying the cllmates of that coast. The force of this remark will be apparent from the following mean temperatures:Helston, $53^{\circ} \cdot 9$; Truro, $52^{\circ} \cdot 2$; Torquay, $51^{\circ} \cdot 6$; Sidmouth, $51^{\circ} \cdot$ i Bournemouth, $51^{\circ} \cdot 5$; Ventnor, $52^{\circ} .4$; and Worthing and Eastbourne, both $50^{\circ} \cdot 7$. It is perhaps scarcely necessary to remark that it would be a mistake to attempt to draw any conclusion from differences of mean temperatures of different stations amounting to $\mathrm{C}^{\circ} \cdot 3$ and under, seeing that the English observations generally were made with thermometers in protecting-boxes quite open on one side, and therefore exposed in varying degrees to indirect radiation from walls and other objects.

While Mr. Eaton has thus failed to prove from past observations that the consumption of fuel and the massing together of living beings in London has raised the mean temperature at Greenwich Observatory to the extent of half a degree, or indeed to any appreciable extent, above that of the south-east of Eng. land generally, it might nevertheless be well, seeing the question has been raised, to do something towards definitely answering it, by instituting at Greenwich and at about a dozen stations distributed over the south-east of England, observations of the temperature of the air, strict uniformity being secured by employing the same pattern of thermometer-box and by placing it under the same conditions at each place as regards height above the 